\title{
Molybdenum isotope budget of arc derived differentiates and cumulates
}

\author{
JULIAN-CHRISTOPHER STORCK ${ }^{1}$, DR. NICOLAS \\ DAVID GREBER ${ }^{1}$, MASSIMO TIEPOLO ${ }^{2}$ AND THOMAS \\ PETTKE $^{1}$
}

${ }^{1}$ University of Bern

${ }^{2}$ Università degli Studi di Milano

Presenting Author: julian.storck@geo.unibe.ch

Differentiation of primitive basaltic magmas is a fundamental process contributing to the production of intermediate to silicarich rocks. Changing pressure, temperature, and $f \mathrm{O}_{2}$ conditions induce crystallization-differentiation of hydrous magmas on their pathway through the crust. As a consequence, cumulates derived from crystallization of mafic minerals (e.g., olivine, clinopyroxene, amphiboles, Fe-Ti oxides) segregate while the melt evolves to silica-rich compositions. For many nontraditional stable isotope systems fractionation associated with igneous processes is documented, indicating their potential to advance our understanding of magmatic differentiation and element cycling in subduction zones [1].

We present a Mo isotope dataset of the magmatic differentiation suite of the Kos Plateau Tuff (Aegean arc) and compare them with upper crustal mafic cumulates from the Sanandaj Sirjan Zone (Iran), the Alpine Orogen (Italy) and the Sierra Nevada Batholith (USA). The detailed dataset sheds light on key minerals that fractionate Mo isotopes as a consequence of magma differentiation and late stage fluid exsolution. Furthermore, the crustal derived mafic cumulates reported here are overall isotopically lighter than the average (granitic) upper continental crust, but heavier than the depleted and primitive mantle.

Our study therefore offers new insights into reported discrepancies between heavy and light $\mathrm{d}^{98 / 95} \mathrm{Mo}$ reservoir formation of emerging modern arc crust. This information becomes a major factor when running Mo isotope based crustal extraction models from a depleted mantle [2] and helps to refine future mantle-crust mass balance calculations.

[1] Teng, F. Z., Dauphas, N., \& Watkins, J. M. (2017). Nontraditional stable isotopes: retrospective and prospective. Reviews in mineralogy and geochemistry, 82(1), 1-26.

[2] McCoy-West, A.J., Chowdhury, P., Burton, K.W., Sossi, P., Nowell, G.M., Fitton, J.G., Kerr, A.C., Cawood, P.A. and Williams, H.M., (2019): Extensive crustal extraction in Earth's early history inferred from molybdenum isotopes. Nature Geoscience, 12(11), 946-951. 